\title{
SALZBURG INSPIRIERT REFERENTEN
}

\section{Liebe Kolleginnen, liebe Kollegen!}

Wie auch im vergangenen Jahr haben sich die Referenten der diesjährigen Kursreihe zum fachlichen Austausch getroffen. Dieses Jahr durften wir in die Atmosphäre von Salzburg eintauchen und uns auf Einladung des Forums Via Sanitas in den Räumen desVereins treffen, um lebhaft $\mathrm{zu}$ diskutieren und Ideen für die neue Homepage und die Kursreihe 2019/2020 zu sammeln. An dieser Stelle möchte ich mich auch für den Einsatz von Frau U. Köstler und Herrn Dr. M. Gstöttner im Rahmen dieser Schulung bedanken. Mit viel Freude und Engagement haben wir die gemeinsame Zeit verbracht. Die Ergebnisse dieser Arbeit werden Sie mit Freischaltung der Homepage im Sommer und in den diesjährigen Kursen erleben dürfen.

REFRESHER-KURS mit A-DIPLOM 3.-5. Mai 2019 | Bitte beachten Sie, dass die diesjährige Möglichkeit, ein A-Diplom abzulegen, im Rahmen des Refresher-Kurses in Waren gegeben ist. Die Einladung sollten Sie schon erreicht haben.An der Mecklenburger-Seenplatte in wunderschöner Landschaft sich vier Tage ganz aufAkupunktur einzulassen, ist nicht nur fachlich ein Vergnügen. Das intensive Training an Arbeitsstationen macht Akupunktur erfahrbar und stärkt Ihre Sicherheit im Umgang mit der Nadel. Davon profitieren Ihre Patienten. Mit dem A-Diplom werden Sie auch in unsere Ärzteliste aufgenommen und sind so für Patienten auffindbar.

\section{AKUPUNKTURÄRZTE-ORCHESTER TIMMEN-} DORF 2019 | Wir wollen mit Ihrem musikalischen Talent und unter der musikalischen Leitung von unserem Kollegen Herrn Wolfgang Ellenberger einen musikalischen Abend für Patienten gestalten, der in Kurzvorträgen zwischen den Musikstücken über die Möglichkeiten der Akupunktur als Therapieform informiert. Seien Sie mit dabei, wenn es auf dem Akupunkturkongress in Timmendorf

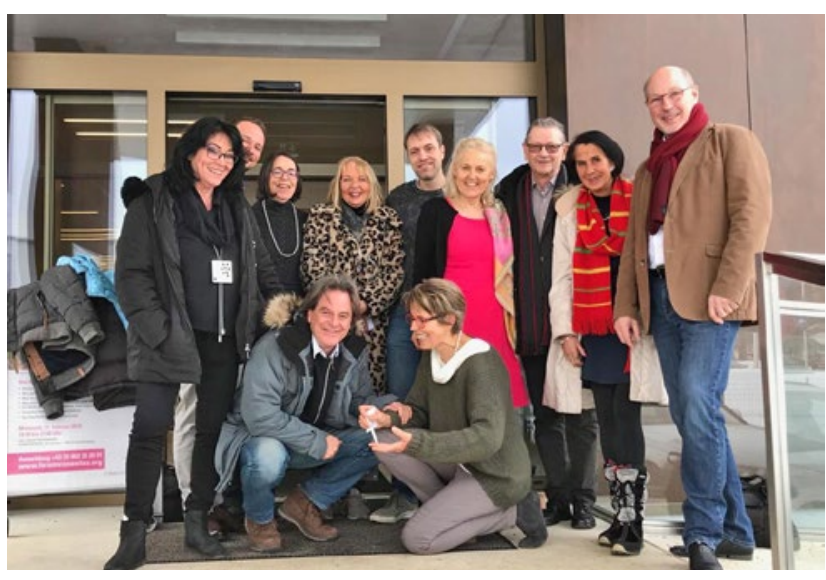

Abb. 1: Referentenschulung in Salzburg

(8.-13.09.19) heißt: Gemeinsam lernen, Gemeinsam diskutieren, Gemeinsam musizieren - Qi-Stagnation beseitigen.

\section{Die DAA-B informiert:}

Der 121. Deutsche Ärztetag 2018 hat festgestellt, dass bis zum Abschluss der Arbeiten derWissenschaftlichen Kommission für ein modernes Gebührensystem (KOMV) nicht mit einer Novellierung der GOÄ zu rechnen ist.Trotzdem gehen die Arbeiten an der neuen GOÄ weiter. Zum Sommer 2019 sollen die Berufsverbände erneut zur Diskussion eingeladen werden, um den bis dahin erfolgten Transkodierungsprozess und die Hochrechnungen dazu kritisch zu bewerten.

Mit guten Wünschen für das Frühjahr

Ihr

B. Ramme

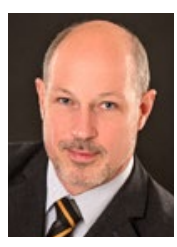

Dr. med. Bernd Ramme

1. Vorsitzender der DAA e.V.

Osserstraße 40, D-81679 München

Tel. $+4989 / 8145252$

E-Mail des allg.Büros: kontakt@akupunktur.de, Internet:www.akupunktur.de 